\title{
Reading Gender by the Column Inch: Analyzing Gender Representation in Philippine Print Advertisements
}

\author{
Czekaina Esrah Rapanot, Fernando Paragas,
} Marrhon Mangalus, Catherine Faith Hoggang, and Mariam Jayne Agonos

\begin{abstract}
The bulk of literature on reading gender in print advertisements studies magazines, which are a media form tailored for specific audiences. By analyzing gender representations in Philippine newspaper ads, this study aims to provide a reading of gender portrayals published in a more general interest medium. Results of the content analysis performed on 256 ads that appeared in top local publications revealed that while gendered inequalities did not strongly manifest in terms of character count and gender distribution, a closer reading of characters and their gendered differences with specific ad elements in terms of contexts, roles, and physicalities evidence the persistence of stereotypical gender representations in print ads.
\end{abstract}

Keywords: print advertising, gender portrayals, gender stereotypes, Philippine print media, advertising in the Philippines 


\section{Plaridel Open Access Policy Statement}

As a service to authors, contributors, and the community, Plaridel: A Philippine Journal of Communication, Media, and Society provides open access to all its content. To ensure that all articles are accessible to readers and researchers, these are available for viewing and download (except Early View) from the Plaridel journal website, provided that the journal is properly cited as the original source and that the downloaded content is not modified or used for commercial purposes. Plaridel, published by the University of the Philippines College of Mass Communication is licensed under Creative Commons Attribution-NonCommercial-NoDerivatives 4.0 International License (https://creativecommons.org/ licenses/by-nc-nd/4.0/legalcode).

\section{How to cite this article in APA}

Rapanot, C.E., Paragas, F., Mangalus, M., Hoggang, C.F., \& Agonos, M.J (2020). Reading gender by the column inch: Analyzing gender representation in Philippine print advertisements. Plaridel, 18(1), 265-293. https://doi.org/10.52518/2021.18.1-04rpahm 


\section{Introduction}

Magazines and newspapers have long comprised the subjects of advertising research, as print media boosted the growth of advertising during the late 1800 s to the early 1900s (Nyilasy, King, \& Reid, 2011). Advancements in media technologies - such as how photography and color printing allowed for more visual print elements, and how the emergence of electronic media like radio and television complemented print as platforms for information dissemination-did not just bring forth the development of the media itself but of the advertising industry that evolved along with it (Lent, 1969; Pollay, 1985; Schwarzkopf, 2011). By the dawn of the $20^{\text {th }}$ century, advertising and marketing rose to be their own fields of expertise that birthed professionals - who, in turn, founded their own agencies-that specialize in the art of selling (Lent, 1969; Pollay, 1985). In recent years, the dynamically evolving landscape of business management, market research, and communication technologies has paved the way for modern media specialist agencies outsourced by (instead of being integrated to) their client companies (Calero-Racho, 2004). The history of advertising, then, is heavily intertwined with the history of mass media - a multifaceted narrative where print media plays a consequential role.

From the field of advertising also stemmed a n array of societal phenomena and research areas concerning advertising's relation to political, economic, and cultural matters that are not always accounted for in advertising history centered on medium and content (Schwarzkopf, 2011). For one, advertising reflects culture (Callow \& Schiffman, 2002; Chen, Chen, \& Cañete, 2017; Frith \& Wesson, 1991; Frith, Shaw, \& Cheng, 2005; Jhally, 1995; Khairullah \& Khairullah, 2003; Marquez, 1975) and advertising strategies are shaped by changing socio-historical contexts (Frith, 1997; Gross \& Sheth, 1989; Lent, 1969; Pollay, 1985; Schwarzkopf, 2011) as well as power relations within the context of globalization (Gross \& Sheth, 1989; Schwarzkopf, 2011; Yan \& Bissell, 2014). Importantly, advertising content is not devoid of the manifestations of advertisers' interests and biases (Soar, 2000; Zayer \& Coleman, 2015). Representations of people, spaces, and situations in advertisements are amalgamations of socially constructed notions and advertising professionals' creative choices, along with their respective clients' branding preferences. The reciprocal process of meaning-making between the agents that create ads and the audience who consume the ads, situated within the context of societal norms, can then reinforce such norms. Unfortunately, these norms can also be stereotypes that perpetuate problematic depictions of certain groups of people.

A heavily studied area in print advertising research is social issues involving the portrayals of gender, race, and consumer protection (Nyilasy, 
King, \& Reid, 2011). Given the power of media to influence attitudes and behaviors, images popularized through advertising that reflect stereotypes and inequalities raise a point of objection for societal sectors that are underand/or misrepresented in advertisements. One such matter that has been extensively explored through research is the representation of gender in advertisements, under which fall the themes of women being portrayed as weak and passive in often decorative roles (Belkaoui \& Belkaoui, 1976; Mager \& Helgeson, 2011; Morris, 2006; Plakoyiannaki \& Zotos, 2009; Zotos \& Tsichla, 2014a, 2014b), and beauty being constructed around both local culture (Krishen, LaTour, \& Alishah, 2014; Lin, 2008) and Western ideals (Frith, Shaw, \& Cheng, 2005; Millard, 2009; Yan \& Bissell, 2014).

This study looks into gendered representations in newspaper advertisements in the Philippines, contributing to the bulk of literature on print advertising that mostly analyze magazines instead-a medium that comes in specific genres with distinguishable target audiences. By utilizing Philippine dailies, this study aims to provide a snapshot of what is visually advertised in a medium of general public interest and how such advertisements portray gendered characters in still images relative to varying product categories. Additionally, cultural aspects of advertisements in the Philippines are discussed and briefly compared with findings from advertising literature across the globe. By delving into print as a platform for advertising, this study also weighs in on the discourse of print's decline as a medium of mass communication. The following subsections provide further context to the study by tackling the intersections of print and digital media, the significance of culture in advertising, and the representation of gender in multicultural print media advertising contexts.

\section{Digital media: print's impending doom?}

Presently, the prominence of digital technology perpetuates a notion that print is now a 'dying' medium as people seem to be ditching newspapers and magazines for online content. As the Internet became the new ground for information dissemination, publications also adopted an online persona. Notably, online platforms enabled the existence of publishing that is solely digital, which also made the experience of publishing more accessible to groups of shared interests or advocacies, alternative/independent media collectives, and even individuals.

In the Philippines, newspaper readership has declined within the past six years (Print, n.d.; Philippine Statistics Authority [PSA], 2019). The most recent Functional Literacy, Education, and Mass Media Survey (FLEMMS) of the Philippine Statistics Authority (PSA) revealed that newspaper reading was one of the mass media engagements that Filipinos do the least, while 
watching television and listening to the radio belonged to what they do the most. On a daily basis, Filipinos were found to mostly watch TV and use the Internet for social media. Moreover, the same report showed that two in five Filipinos enrolled in school (i.e., aged 10-30) never read a newspaper in 2019 and that newspapers were the media form they were least exposed to, while their level of exposure to magazines came at a distant second to TVthe medium to which they were most exposed (PSA, 2019). Overall, the Filipino majority's primary sources of information are still traditional media (i.e., TV, radio, and print in the form of newspapers and magazines), which they trust more than digital media platforms (i.e., social media, online news sites, and blogs) (EON Group, 2019). However, print falls behind its peers in the traditional media category, and its digital counterparts now seem to be gaining popularity.

While it is plausible to associate the declining readership of physically printed copies with the purported "death" of print media, such argument constrains the notion of "print" within its materiality. John O'Sullivan et al. (2017) argue that the "death of print" narrative is conceptually mistaken because it fails to acknowledge how digital technology improves the printing process and how digital content is produced through print-based journalistic culture (e.g., in newsrooms) in a complex, complementary fashion. Physical copies and online versions of content from the same publishers-be they news agencies or subscription magazines, and the like-provide distinct experiences surrounding the interactivity of media content as well as the manipulability and sensoriality of media forms (O'Sullivan et al., 2017). From this more constructivist perspective, "print media," then, goes beyond the physicality of printed materials to include an entire culture of transmediality rooted in the art not just of printing per se but of writing for print. "Readership" would then include engagement with the online counterparts of print outlets. That the online platforms of the three broadsheets in the Philippines' ten most read newspapers are also the most visited news sites in the country (Print, n.d.) merits credence in the evolution, not death, of print media. The increasing popularity of online subscriptions to news agencies, the inclusion of digital elements in print materials (e.g., QR codes on newspapers), the opportunities provided by digital algorithmic news writing that enable journalists to produce more in-depth and investigative works, and the online platforms breaking the unidirectionality of print media present how the digital complements and maximizes print instead of rendering it obsolete (O'Sullivan et al., 2017). Hence, print media remains to be a significant collection of platforms for advertising, which underwent its own evolution as an art and an industry. 


\section{Advertising and culture}

Images created for, presented in, and distributed through mass media not only cultivate culture, they can also specifically cultivate a consumerist culture (Jhally, 1995; Wood \& Fixmer-Oraiz, 2017). In driving people to consumption, advertising has become as ubiquitous as media content itself. Business models in today's age of new media capitalize on people's attachment to devices by inserting ads in all possible places and putting up subscription costs to allow people to go "ad-free." Subtly intrusive algorithms also make use of users' data-be they personal information, search and watch histories, social media usage patterns, and even what transpires in people's face-to-face conversations by listening through devices' built-in microphones - to tailor fit the ads every single user sees in their feeds. The advertisements people consume through digital media work side-by-side with the ads people see in traditional media, like commercials on TV and radio and ads in newspapers and magazines, as well as out-of-home ads like billboards and other non-traditional methods like sticker marketing.

While media creates and reinforces culture, media representations are also very much shaped by culture. A significant part of an advertisement's appeal rests on how it draws from and relates to its audiences' cultural realities (Callow \& Schiffman, 2002). Manifestations of values in print advertisements have been found to reflect both differences and similarities between cultures-as in the cases of India and the US (Khairullah \& Khairullah, 2003), the US and Britain (Frith \& Wesson, 1991), and Taiwan and the Philippines (Chen et al., 2017). Also, culture manifests in how audiences read advertisements. By comparing Filipino audiences' interpretations of ads-with Filipino culture classified as high-context-and Americanswith American culture classified as low-context-Michael Callow \& Leon Schiffman (2002) found that Filipinos were able to discern deeper meaning from ad images than their American counterparts did.

The Philippines presents an interesting case in cultural representation in advertising. Despite belonging to a generally high-context culture, Filipinos were classified by Chih-Ping Chen et al. (2017) as low-context because of the country's significantly Westernized culture brought about by its long colonial history. In their comparison of Philippine and Taiwanese ads, it was the Philippines that represented a "Western" perspective between the two Asian countries (Chen et al., 2017). Moreover, in the earlier days of advertising in the Philippines, ads in local newspapers and magazines were found to reflect Western instead of indigenous values (Marquez, 1975). It is a straightforward assumption that the preeminence of Western imagery in Philippine ads is an evidence of colonial influence. However, while such assumption is valid, it fails to acknowledge that advertising is deeply rooted 
and oriented in Western culture (Marquez, 1975), and that the Westspecifically US-based advertising hubs-is the industry's reference point for what can be considered "global" (Schwarzkopf, 2011).

From a macro perspective, cultural representation in advertisements is two-fold: it includes reflections of a nuanced local culture, and also features standardized character depictions shaped within the larger context of globalization. While responses to globalized advertising strategies vary culturally and merit a rethinking of the standardization of ads (Callow \& Schiffman, 2002; Frith \& Wesson, 1991), the dominant visual and textual cues in advertising reveal that advertising caters to a nation's middle to upper class urban elite who carry purchasing power (Khairullah \& Khairullah, 2003). Under capitalism, it can be perceived that social status enables a shared culture in the context of consumption-a culture that champions values on how one should manage financial resources.

\section{Gender representation in print advertising}

An aspect of culture extensively problematized and theorized about in the context of advertising is gender. In contrast to sex that is a biological classification, gender is a matter of performance-that is, how people behave and present themselves according to socially constructed notions of femininity and masculinity greatly interrelated with sex (Goffman, 1976/1987; West \& Zimmerman, 1987). In particular, Erving Goffman $(1976 / 1987)$ writes that "if gender be defined as the culturally established correlates of sex (whether in consequence of biology or learning), then gender display refers to conventionalized portrayals of these correlates" (p. 1, emphasis added). The societal dictates of gender displays have been compelling enough to make people conform to the binary of "male" and "female" identities. Displays, with their dialogic character that sets up expectations of normalized responses, entail consequences for deviance (Goffman, 1976/1987) despite being an optional activity for individuals (West \& Zimmerman, 1987).

The "commodity image-system" of advertising, which reinforces the notion of defining a person based on what they own, has distorted perceptions of gender by presenting how men and women are assumed to behave instead of how they authentically behave vis-à-vis the products they are encouraged to consume (Jhally, 1995). Advertising has exploited the concept of gender by assigning what products are "for him" and "for her," feeding the public images of men and women in dichotomized bodies, roles, activities, and situations. However, what makes ads perpetuate a gendered consumerist culture among its audiences are the often overlooked players in the field of representation in advertising: the ad creators themselves. In 
the previous section on advertising and culture, it was discussed that ads are made relatable to audiences by drawing from cultural realities. Fleshing out this common truth, it can be discerned that the creative professionals who produce ads must be the same people who decide what elements of "culture" should appear in one. True enough, Linda Zayer and Catherine Coleman (2015) discovered that ads can be shaped by how different types of advertisers perceive gender, how they think gendered portrayals impact audiences, and what they believe they can do to improve gender representation in ads.

Initiating cultural change within the industry will not come easily. Advertising professionals themselves form an elite cultural group who work under standards they agree upon and are hence motivated to meet such standards to gain approval from their peers (Soar, 2000). Therefore, what audiences see in ads are not always driven by an intention to promote products but an ad creator's desire to impress their own community of advertising creatives (Soar, 2000; Zayer \& Coleman, 2015). Various interests - of advertisers, of clients, of target audiences, and of the general public-are at play in the creation of ads, in a complex, multifaceted process of advertising influencing cultural norms, culture shaping people's perceptions, and people controlling the advertising industry.

Throughout the history of gender portrayals in print ads, women have long been depicted as subordinate and treated as decorative (Belkaoui \& Belkaoui, 1976; Goffman, 1976/1987; Grau \& Zotos, 2016; Kang, 1997; Mager \& Helgeson, 2011; Morris, 2006; Plakoyiannaki \& Zotos, 2009; Stankiewicz \& Rosselli, 2008; Zotos \& Tsichla, 2014a, 2014b), and sexualized and subjected to male dominance (Frith, Shaw, \& Cheng, 2005; Kang, 1997; Lin, 2008; Mager \& Helgeson, 2011). Gendered ad images have created gendered classifications of non-gendered ad elements like product categories and reinforced stereotypically culture-bound gender roles in society as in occupations and relationships (Belkaoui \& Belkaoui, 1976; Grau \& Zotos, 2016; Morris, 2006; Plakoyiannaki \& Zotos, 2009; Robinson \& Hunter, 2008; Zotos \& Tsichla, 2014b). Notably, advertising has capitalized heavily on an exploited image of a woman tied to impossible ideals.

Scrutinizing the portrayal of gender in print advertisements is the foundation of Goffman's (1976/1987) widely cited work in the fields of gender studies and advertising research, in which he identified five aspects of an ad where women are depicted disadvantageously:

1) Relative size, which refers to characters' height and heft relative to other characters in the ad;

2) Use of hands, which pertains to a characters' manner of touching 
things or other characters; this can be classified as ritualistic (as in gracefully caressing or "barely touching" objects or people), or utilitarian (as in grasping, holding, or manipulating objects in a more functional and assertive manner);

3) Function ranking, which denotes one's gender role in relation to another character shown with them; this can be classified as dominant (i.e., in active roles and displays of competence and authority) or subordinate (i.e., at the receiving end of active roles, in displays of incompetence and neediness);

4) Licensed withdrawal, which pertains to a character's psychological engagement with other characters and/or the situation; this can be portrayed in several ways, like appearing spaced out or lost in one's thoughts (gazing away from the camera), or shy, fearful, or childish (looking or peeking from behind objects or over one's shoulder;

5) Ritualization of subordination, which refers to how an individual character is positioned and/or how their body is made to look; this can be classified as authoritative, when a character displays a fierce look with a confident posture (e.g., erect body with the head held high and chin up), or submissive, when a character appears in lowered or distorted postures, childlike poses, and reclining positions (e.g., on fours or laid flat).

Using these variables, Goffman (1976/1987) asserts that advertisements often portray women as small, delicate, disengaged, and submissive. There is, however, a criticism that Goffman's sample is skewed towards depicting characters according to what the variables expect of them (Kang, 1997). Yet, in utilizing Goffman's variables-and adding two more, which are Body Display (i.e., what parts of a character's body or how much of their skin is exposed) and Independence/Self-Assertiveness (i.e., a deeper reading of a character's portrayal relative to the values of independence and selfassertiveness) - to study magazine ads from the year 1991, Mee-Eun Kang (1997) found little differences between her study and Goffman's. Notably, the ads featured even more depictions of women appearing withdrawn (Licensed Withdrawal) and sexy or nude (Body Display). While most of Goffman's assertions held true, it is also interesting to note that Kang's research revealed that Relative Size and Function Ranking were not prevalent likely due to ads presenting males and females individually instead of within interactional contexts.

Despite signs of decline in gendered portrayals unfair to women being evidenced in historical and comparative studies of print ads, that women remain unequal to men show a hesitance to shatter gender stereotypes 
in advertising (Belkaoui \& Belkaoui, 1976; Grau \& Zotos, 2016; Mager \& Helgeson, 2011). A case in point is the idealization of beauty-created by both native constructions and globalized images (Chen, Chen, \& Cañete, 2017; Frith, Shaw, \& Cheng, 2005; Krishen, LaTour, \& Alishah, 2014; Yan \& Bissell, 2014) - which subjects women to an unending pursuit of physical perfection. Regardless of the rise of more empowerment-themed ads, the intent of advertising to draw people into consumption renders advocacy questionable especially in the light of company ethics and labor exploitation in the process of production (Grau \& Zotos, 2016; Millard, 2009). Within the discourse of empowerment emerges the issue of a woman's double burden, where she is encouraged to be economically productive yet still be expected to take on her traditional, domestic responsibilities.

\section{Methodology}

Kim, Hayes, Avant, \& Reid (2014) found that advertising studies published in academic journals from 1980 to 2010 were more empirical and quantitative, and content analysis emerged as one of the predominant methods, next to lab experiments and surveys, in advertising research. They explained further that not only did quantitative approaches become more popular in the field of advertising over the years, implications in academic research works have also been "directed toward practitioners, not theorists or methodologists" (p. 310), which possibly explains the prioritization of generalizable and quantifiable data. Nonetheless, the practice of content analysis has evolved and coding processes have also been modified to accommodate a deeper reading of messages embedded in media content. For cross-cultural advertising research, for example, Dawn Lerman and Michael Callow (2004) recommended a process called narrative coding, where subjects from the target audience interpret ads, instead of judges who may not be able to recognize cultural nuances in ad content or interpret the ad messages according to the culture they are expected to represent. There can be more critical and/or interpretive ways of reading advertisements, which can also be more qualitative in approach, but for the purposes of this study, the researchers employed content analysis with a culturally contextualized coding process to be able to provide an initial and general image of gender representation in Philippine print advertisements.

This study examined a total of 256 print ads published in top Philippine newspapers in 2018. The ads were chosen through constructed week sampling, where a week of randomly selected dates corresponding to each day of the week is created to represent a specific time frame. This study generated two constructed weeks from 1 January to 31 December 2018 and collected unique ads from three broadsheets (Philippine Daily 
Inquirer, Philippine Star, and Manila Bulletin) and two tabloids (Pilipino Star Ngayon and Bulgar). The ad copies were provided by Aries Insights and Media Solutions, Inc. (AIMS), acquired with the assistance of leading research agency Kantar Media. The sample excluded duplications and ads that did not feature humanoid ${ }^{1}$ characters. $^{2}$

\section{Instrumentation and coding}

The study investigated two units of analysis: 1) the advertisement in its entirety, and 2) the characters featured in an ad. A total of 27 variables were coded for each ad, with 11 ad-level variables and 16 character-level variables. Since this study is part of a bigger research project that analyzed legacy media ads, the variables identified for print are mostly shared with TV, with the two both being visual platforms. Nonetheless, in examining gender representation, the coding guide for print included four of Goffman's variables, as adapted from John Mager and James Helgeson (2011). These variables are: use of hands, function ranking, ritualization of subordination, and licensed withdrawal. A summary of all variables coded in this study, including a brief description of each, can be found in Appendix A.

Through a rigorous process of instrumentation, the major difference between Philippine ads and Western ads was taken into account. Western studies in advertising tend to select main characters from the very start of the coding process, a practice that proved to be difficult in the Philippine context, given that local ads were observed to have numerous characters within a single ad. To address this cultural nuance, advertisement composition and (character) prominence were coded first, before determining standoutswhich would then be the subjects of coding for the character-level variables.

The coding process for this study did not exactly follow Lerman and Callow's (2004) narrative coding approach by employing audience members to interpret the ads, but all data encoders were Philippine-based bilingual Filipinos who are exposed to local ads. Hence, they are a part of the Filipino target market, whose cultural sensibilities can also reflect that of a Filipino viewing public. It must be noted that the study itself is anchored in visual messaging (i.e., how humanoid characters are presented in each ad), hence the elimination of text-only ads and ads without humanoid images in the sample. The more "narrative" type of coding was employed only for the identification and classification of ad pitch themes.

The data encoders were student assistants of communication research selected from an undergraduate quantitative research class. They were trained by the research team prior to the intercoder reliability testing. Through an iterative process of coding, calculating for reliability, debriefing, and retraining, the data encoders achieved a Krippendorf's alpha coefficient 
of at least 0.787 for all intended variables except three: Product User Gender (ad-level), Sexual Objectification (ad-level), and Pregnant with Infant (character-level) - all having showed no variation and were hence considered as constants. These three variables were subsequently excluded in the final coding guide. The data encoders had an average reliability score of 0.870 . The final reliability scores for each variable ${ }^{2}$ are shown in Table 1.

Table 1. Intercoder reliability scores .

\begin{tabular}{lc}
\hline \multicolumn{1}{c}{ Variable } & Reliability score \\
\hline Ad-level variables & \\
\hline Product Category & No Variation \\
Product User Gender & 0.870 \\
Attraction & No Variation \\
Sexual Objectification & 0.957 \\
Ad Composition & 0.828 \\
Prominence & 0.873 \\
Standouts & \\
Character-level variables & 0.888 \\
Character Identification & \\
Setting & \\
Credibility & 0.863 \\
Gender & 0.837 \\
Age & 0.912 \\
Social Class & 0.858 \\
Pregnant with Infant & 0.803 \\
Body Type & No Variation \\
Body Shown & 0.832 \\
Attire & 0.916 \\
Occupation & 0.787 \\
Relational Role & 0.904 \\
Familial Responsibility & 0.878 \\
Use of Hands & 1.000 \\
Function Ranking & 0.902 \\
Litualization of Subordination & 0.921 \\
\hline
\end{tabular}




\section{Results and Discussion}

The research findings are discussed in themes of gendered contexts-who the characters are and where they are found; gendered roles-what the characters are doing; and gendered bodies - how the characters are portrayed in physical terms. In several variables with predetermined categories, the top result featured ads in unspecified or undeterminable options (e.g., "Others"/"None"), so the comparisons across gender are made within smaller subsets of the sample with a difference of at least three percentage points.

\section{Overview of ads}

Most of the advertisements were found to appear solely in broadsheets (84.0\%), with less than a quarter appearing in tabloids $(13.7 \%)$ and in both publications (2.3\%). The seeming lack of variance may be due to the wide time frame for the circulation of ads in newspapers that makes the same ads appear throughout the year, as well as brands using very similar iterations of ads for their products. More than half of the print ads had no clear pitch theme (52.7\%), but for those with at least one, the top pitch themes found are as follows: value for money (sulit $\left.{ }^{\circ}\right)(9.8 \%)$, values-oriented $(9.5 \%)$, and product/brand prestige $(8.7 \%)$. Philippine print ads have been found to persuade audiences indirectly through claims of product effectivity (Dayag, 2008), personal appeals (Marquez, 1975), as well as appeals to emotional needs and a regard for prestige (Fernandez, 2016). The present study's results coincide with previous findings, showing that print ads in the country highlight the importance of being a savvy consumer, relate to audiences through a more emotional approach to persuasion, and convince consumers by emphasizing product efficiency that presumably justifies purchase. Notably, almost all (92\%) of the characters were shown as members of the upper middle class, echoing Khairullah \& Khairullah's (2003) assertion that advertisements, despite the cultural nuances that influence their textual and visual components, are generally governed by an intent to cater to the economically advantaged.

\section{Gendered contexts}

On ad composition and gender distribution. More than a third of the ads featured roughly equal mixed pairs/groups of men and women (35.9\%). Ads exclusively composed of women (34.0\%) were more than those exclusively composed of men (29.7\%), with characters appearing either individually, in pairs, or in groups.

At the character level, the majority of the characters were cisgender men (53.6\%) while almost half were cisgender women (46.4\%). It is worth noting that while identification of non-cisgender characters was present in 
the gender variable, no such characters were found in any of the ads. Almost half of the characters appeared solo (49.6\%), with solo females (27.3\%) outnumbering solo males (22.3\%) by a several percentage points.

That ads featuring mixed pairs and groups showed a considerably equal distribution of men and women, and that more than half of the ads featured men and women exclusively, lend credence to Kang's (1997) observation that advertisements are continually being tailored for specific audiences. Additionally, this is possibly a result of the platform's spatial limitations. Advertising in print is monetized by the column inch, which requires a practical and strategic use of space. Gendered notions surrounding product categories may have been motivating what ads emphasize visually-hence the prevalence of solo ad characters and exclusively gendered groups promoting specific products.

On gender, product categories, and ad pitch. The highest number of ads fell outside the study's pre-determined product categories $(28.1 \%)$. Excluding those ads, however, the top product categories featured were recreational products and services (16.8\%), private services (13.3\%), and automotive and fuels (10.9\%).

Gender distribution of characters varied slightly within product categories. Exclusively female ads topped exclusively male and mixed pair/ group ads in recreational products and services ( $20.7 \%$ vs. $18.4 \%$ vs. $12.0 \%)$, restaurants, retail outlets, and malls ( $10.3 \%$ vs. $1.3 \%$ vs. $4.3 \%)$, and real estate $(10.3 \%$ vs. $0.0 \%$ vs. $7.6 \%)$. This is replicated at the character level, as more women than men appeared in ads for recreational products and services ( $22.5 \%$ vs. $19.9 \%)$, restaurants, retail outlets, and malls ( $4.7 \%$ vs. $2.8 \%)$, and real estate $(10.8 \%$ vs. $3.7 \%)$. Meanwhile, mixed pair/groups were found ahead of exclusively male and female ads in private services (15.2\% vs. $13.2 \%$ vs. $11.5 \%)$ and government ads ( $13.0 \%$ vs. $1.3 \%$ vs. $2.3 \%)$. Government ads become dominated by men $(9.8 \%$ vs. $6.6 \%)$ at the character level. Among product pitches, women outnumber men in advertising beauty and youth (3.8\% vs. $0.4 \%)$, experience/lifestyle ( $7.5 \%$ vs. $4.5 \%)$, and value for money (sulit) (13.6\% vs. 6.1\%). Meanwhile, men outnumber women in advertising product/brand prestige (10.2\% vs. $7.5 \%)$.

Women appearing more often for products for recreation and venues for leisure, as well as for product pitches surrounding physical attractiveness and lifestyle, reflects the advertising trend of women being associated with products linked to gratification (Belkaoui \& Belkaoui, 1976; Plakoyiannaki \& Zotos, 2009). The data also shows how women are still expected to be youthful and almost ageless (Fernandez, 2016). Additionally, the association of women with the value for money (sulit) pitch evidences a domestic duty 
expected of women - that of managing the family's finances, hence having to be a practical housekeeper, or in Filipino terms, a wais ${ }^{7}$ consumer.

On gender and setting. More women than men appeared in nature (10.3\% vs. $3.3 \%)$, recreation and wellness (6.6\% vs. $3.7 \%)$, and generic $(14.6 \%$ vs. $8.5 \%)$ settings. More men than women were presented in $\operatorname{limbo}^{8}(56.9 \%$ vs. $37.6 \%)$. Interestingly, men and women were equally shown in the rest of the settings-including the home, which has been a heavily gendered setting in advertisements. Throughout the last 50 years of print advertising, a decline in the portrayal of the home as a woman's domain was recently observed (Mager \& Helgeson, 2011), although much is left to delineate in terms of the roles men and women take within the home and familial relationships (Robinson \& Hunter, 2008).

\section{Gendered Roles}

On gendered roles. The majority of characters did not assume specific relational roles $(51.9 \%)$, relating to the finding that most of these characters appeared solo. Women appeared in recreational roles more than men $(23.0 \%$ vs. $16.3 \%)$, while men outnumbered women in professional roles (14.2\% vs. $7.0 \%)$. Both men and women took familial roles roughly equally (17.5\% vs. $18.3 \%)$.

The association of men with a professional-or at the very least, employed-status has been prevalent in print advertising throughout decades across the globe (Belkaoui \& Belkaoui, 1976; Morris, 2006), reinforcing how occupation remained to be a heavily gendered image in advertisements (Grau \& Zotos, 2016). However, the increasing economic participation of women in society continues to challenge these advertising depictions (Frith, 1997). The portrayal of men's increasing involvement in the family - a realm previously assigned almost exclusively to women - has emerged in more recent advertising trends, albeit this effort appears to be small (Grau \& Zotos, 2016). Nonetheless, that both men and women appeared in familial roles almost equally in Philippine newspaper ads present a shifting perspective in advertising; whether this finding holds in print media of specialized interests (e.g., magazines), however, is for future research to uncover.

On gender, occupations, and credibility. More men than women appeared as models/celebrities $(21.1 \%$ vs. $16.9 \%)$, STEM and ABM professionals (9.8\% vs. 5.2\%), and skilled laborers (6.9\% vs. 1.9\%). Meanwhile, women only appeared more than men as students (6.1\% vs. $3.3 \%)$. It must be noted, however, that the greatest number of both men $(36.2 \%)$ and women (51.2\%) appeared in unspecified occupations. 
Men were presented more as celebrities (24.8\% vs. $14.6 \%)$ and experts (25.6\% vs. $11.3 \%$ ). A big majority of women (73.7\%) were presented as users/ consumers, significantly outnumbering men (49.6\%) in the same category. Women appear to be driven into consumption (Plakoyiannaki \& Zotos, 2009), while men do the persuasion. The dominance of men in credibility positions (i.e., as celebrity endorsers and experts) and in occupational roles that denote credibility and ability (i.e., as professionals and laborers), as well as male characters' association with brand prestige in the study's previous finding on gender and ad pitch, all imply the authority of their masculinity: a man's image holds a higher status in society, and a man's word is to be trusted and followed.

On Goffman's variables. Among the characters who appeared with another character in the ad, $80 \%$ had no clear hierarchical relationship with each other (Function Ranking). Overall, three in four characters were neither submissive nor authoritative (Ritualization of Subordination), and almost three-quarters (74\%) of characters were also not depicted in terms of Licensed Withdrawal. That most characters no longer manifested Goffman's categories in Philippine newspaper advertisements shows an interesting point of inquiry in advertising research. Some of Goffman's original conceptions of gender portrayals in advertising may not appear as salient as they once were, as reflected in existing literature (see Kang, 1997; Mager \& Helgeson, 2011).

In the specific instances of Licensed Withdrawal, though, a tenth of the characters were shown as spaced out (lutang), and this was more pronounced among female (12\%) than male (8\%) characters. A bigger percentage of men (11\%) than women $(6 \%)$ were among the eight percent of characters who had a fierce, focused, alert and/or assertive look. Conversely, a bigger share of female (12\%) than male (5\%) characters were among the eight percent who were shown as over-engaged and without emotional control. This zoomed in view of the data reveals that in the relatively fewer instances of gendered depictions, the stereotypes of women appearing withdrawn more than men still hold (Mager \& Helgeson, 2011).

Additionally, a big majority of characters displayed gendered Use of Hands (71.4\%), with more men seen with a utilitarian touch $(37.4 \%$ vs. $31.5 \%$ ) and more women seen with a ritualistic touch (46.0\% vs. $28.9 \%$ ). The Use of Hands appears to be an enduring depiction of women being decorative elements of ads (Mager \& Helgeson, 2011).

\section{Gendered Physicalities}

On gender and attire. Most characters were shown fully-dressed (87.4\%). Notably, more men than women appeared fully-dressed (93.9\% vs. 
$79.8 \%)$ while more women than men appeared partially-dressed (16.0\% vs. $4.9 \%)$. Within the fully-dressed category, men outnumber women in workrelated uniform (25.6\% vs. $8.0 \%$ ) and casual wear (51.6\% vs. $48.4 \%$ ). Within the partially-dressed category, more women than men appeared in casual wear $(9.9 \%$ vs. $2.0 \%)$. More women than men were also shown seminude (2.8\% vs. $0.4 \%)$.

Philippine traditional values uphold rather conservative principles. Most media regulations in the country adhere to these values, and advertising is no different. The Philippines' Ad Standards Council prohibits the release of ads that feature obscenity, sexually suggestive visuals, and nudity (Ad Standards Council [ASC], 2019). That most characters were shown fullydressed evince adherence to these advertising guidelines. The gendered differences in attire, however, mirror the previous findings on men and women's roles and occupations. Men in work-related uniform signify their association with formal contexts, while women in casual wear show their involvement in more decorative/leisurely activities than "serious" oneslike professional work-and are instead associated with the informalities of the everyday.

On gender, body type, and body shown. A big majority of characters (78.0\%) were shown with ectomorphic (payat) bodies. Comparing characters by gender within specific categories, more women than men appeared ectomorphic $(85.4 \%$ vs. $71.5 \%)$ while more men than women appeared endomorphic (chubby) (22.8\% vs. $13.1 \%)$ and mesomorphic (batak) $(4.1 \%$ vs. $0.5 \%)$. More men than women were shown from the waist up ( $28.9 \%$ vs. $20.7 \%)$, while more women than men were shown with a full body (34.3\% vs. $26.0 \%)$.

Thinness characterizes an ideally beautiful body in advertisements (Conlin \& Bissell, 2014; Millard, 2009; Yan \& Bissell, 2014), which can be harmful when framed as the ideal healthy body as well (Conlin \& Bissell, 2014). The notion of an ideal body and its imposition on women fails to recognize the existence and validity of other body types like athletic and muscular (Conlin \& Bissell, 2014). Men being allowed to carry more endomorphic and mesomorphic bodies associate physical heftiness with masculinity, further associating it to concepts tied to masculinity like authority and control. That women still appear to be limited to being petite and constrained to what is perceived as physically desirable reflects that women remain subjected to social conventions. It must be emphasized, however, that standardized images of beauty portrayed in print advertising heavily draws from Western ideals (Yan \& Bissell, 2014) and evidences the control that the culture of "the West" - where advertising agencies are largely 
based-wields over advertising messages that circulate internationally (Frith, Shaw, \& Cheng, 2005).

On gender and age. Women in print ads appeared as young adults (21-39 years old) more than men ( $73.7 \%$ vs. $46.3 \%)$. Men, meanwhile, outnumbered women in the middle-aged to senior category (43.1\% vs. $11.7 \%)$. Philippine print ads have been found to subject women to an impossible standard of agelessness (Fernandez, 2016), as if aging is not a normal biological process that the human body undergoes, while men are allowed to age visually. Tied to the societal standards of beauty, women are pressured to look youthful which drives them to consume products that make them "look young and feel young."

\section{Conclusion}

This study aimed to present a general picture of gender representation in Philippine print advertisements on both the level of an ad, i.e., its general attributes like product details, pitch themes, and basic visual elements, and the level of an ad's standout characters, i.e., the portrayal of each character in relation to context, role, and physicality. Across these two levels, consistency in gendered messaging has been observed, alongside overarching themes in Philippine culture that manifest in print advertisements. Additionally, the findings revealed methodological insights and practical considerations in the field of advertising.

Notwithstanding the prevalence of undeterminable options (e.g., "Others"/"None") in the results, the gendered differences found between men and women characters surface the subtle reinforcement of gender norms in Philippine print advertising, mirroring a major insight from Western advertising studies (see Belkaoui \& Belkaoui, 1976; Mager \& Hegelson, 2011; Plakoyiannaki \& Zotos, 2009) that women remained portrayed in stereotypical manners despite their increased presence in advertising images. The current findings revealed that women in Philippine print ads are still more associated with themes of recreation, beauty, and youth, which were reflected in contextual ad attributes (i.e., product category, ad pitch), relational character roles, and physical character attributes (i.e., attire, body type, body shown, and age). The notion of beauty in local print ads, drawn from the salience of the ectomorphic (payat) body type and the young adult appearance in the depiction of women, reflects the persistence of standardized ideals in advertising (Conlin \& Bissell, 2014; Frith, Shaw, \& Cheng, 2005; Yan \& Bissell, 2014). Furthermore, women's decorative depictions were evidenced by their more ritualistic use of hands, as well as their more withdrawn appearance in some circumstances. Appearing spaced out and without emotional control also disadvantaged women in the 
context of credibility, where they were also portrayed by a significant margin more as consumers than men. Across variables, masculine credibility was established in how cisgender male characters looked fiercer and more authoritative, were more associated with brand prestige, and appeared more as experts and endorsers. All of these implied a status reflected in their occupational portrayals as professionals and celebrities. The current findings do not expose male dominance in the context of sexualization as previous studies and inquiries have presented (see Frith, Shaw, \& Cheng, 2005; Goffman, 1976/1987; Kang, 1997; Lin, 2008; Mager \& Helgeson, 2011). Instead, gender biases against women evidenced in Philippine print ads persist in the context of social and individual roles (e.g., within specific spaces, occupations, relationships, etc.) where men were portrayed in more functional ways, while women were still portrayed in more decorative ones.

In addition to the contextual shift of gendered portrayals, the unobservability of Goffman's variables in most cases in the present study provides major insights in the development of advertising research. To start with, it subjects Goffman's original visualizations of gender biases to further scrutiny and challenges the variables' relevance to reading visual ads in today's age. However, as much as the manifestation of some of Goffman's variables became less salient, the prevalence of gendered stereotypes in the subset of cases in which they were observed pose a rather intriguing reflection of social reality: despite the increased "representation" of women in ads, the gendered notions surrounding women's bodies and roles in society are still perpetuated in the ways they are presented (Mager \& Helgeson, 2011). The continuous evolution of advertising culture and the development of discourses concerning gender in society call for a recalibration and recontextualization of Goffman's variables.

Gender stereotypes have been found to be universal despite the cultural differences in interpreting and performing gender (see Morris, 2006), and the patterns of gendered biases observed in Philippine print ads demonstrate the dominance of Western standards in international advertising (see Schwarzkopf, 2011). That almost all characters were found to come from the upper middle class also shows how advertising messages are targeted towards audiences with higher economic power and social status (see Khairullah \& Khairullah, 2003), which is unsurprising as advertising operates largely in relation to consumption. The advertisements analyzed in the study surface the Filipino consumerist value of being wais and having a regard for a knowledgeable authority that can persuade one into purchase (see Lent, 1969), with the former characteristic found to be attributed to women and the latter seen to contextualize the implications of men as the image of credibility. It can be inferred, then, that gendered 
narratives in advertisements are also shaped by the commerciality of advertising itself. Women are subjected to the consumption of products through the pressure to conform to beauty and lifestyle ideals. Men are also encouraged to consume through the reinforcement of status in the masculine image. Therefore, gender biases in advertising images-while disadvantaging women and privileging men-generally work in favor of commercial interests.

While it is undeniable that the purpose of advertising is to sell, it can be argued that the body of literature on gender representation in advertisements-often evidencing the persistence of gender stereotypes in various aspects-call upon the advertising industry to fulfill such purpose without perpetuating gender biases. The prevalence of gendered differences found in local print ads surfaces the longstanding burden on women in Philippine society to appear "beautiful" and young at all times, with the notion of beauty both shaped by Western standards and recontextualized in local culture. Hence, those who do not fit into the image of an ideal woman are made to metamorphose into one: their faces must remain without fine lines, their skin must always be smooth and blemish-free, their hair must be kept soft and sleek. Such burden grows as the pressure to conform to beauty standards coexists with expectations regarding women's economic participation alongside their fulfillment of domestic duties. Further, the persistence of showing women in more decorative and less credible roles in ads may imply a similar assumption about women and how they are treated within spaces. It is for future scholarly endeavors to uncover whether or not such an assumption is truly reflective of how women are regarded in Philippine society, or if it is just an assumption that advertising practitioners hold about women; or perhaps both, as these two suppositions can reinforce each other in a complex reciprocal process.

Gender representation in the media must include-in dignified and not tokenistic ways-gender identities outside of the cisgender binary. More importantly, it must place the discourse of representation into the broader context of social change. The increased presence of women and members of the LGBTQ+ community who do not identify and present themselves in a heteronormative fashion, not just in advertisements but in various other forms of media content, must continuously be critiqued to further the realization of equity and inclusivity in how women and queer people are actually treated in society.

\section{Recommendations}

The authors suggest a reconceptualization and recontextualization of Goffman's variables in terms of subtle sexism, the more salient form of 
sexism surfaced in the present study. Additionally, such variables can be reworked to apply in the context of moving images (e.g., TV ads). If taken beyond still images, Goffman's conceptions of gender biases in advertising can bring forth a richer cross-media comparison of visual ads. Gender, in this case, can also be broadened in scope to include queer representations in the media.

Aside from quantitative content anlysis, other methods and approaches can be utilized to study gender representation in advertising. There are countless possibilities for future studies, but the authors wish to highlight two: first, a historical reading of advertisements can reveal the development of gender depictions in local ads across media platforms; second, an indepth study of the narratives of ad creatives-like their perceptions of gender and how such perceptions translate to their work, or their relationships with clients and how client demands shape characters and storylines in advertisements-may surface various aspects of ad production that influence gender representation in local ads.

Given that cultural nuances also manifest in ad content (Chen, Chen, \& Cañete, 2017; Frith, Shaw, \& Cheng, 2005; Frith \& Wesson, 1991; Khairullah \& Khairullah, 2003; Krishen, LaTour, \& Alishah, 2014; Yan \& Bissell, 2014), the authors also recommend that future research delve into the cultural aspect of advertising, as opposed to its mere content and form (Schwarzkopf, 2011). Using quantitative and qualitative approaches complementarily can yield not only generalizable but also culturally nuanced insights that may better reflect the local advertising landscape and gender representation within it, in relation to Philippine socio-historical, socio-cultural, and socio-economic contexts. 


\section{References}

Ad Standards Council (ASC). (2019). ASC guidebook for responsible advertising. https://asc.com.ph/wpcontent/uploads/2016/06/ASC_Guidebook.pdf

Belkaoui, A., \& Belkaoui, J. M. (1976). A comparative analysis of the roles portrayed by women in print advertisements: 1958, 1970, 1972. Journal of Marketing Research, 13(2), 168-172. Retrieved from https://www.jstor.org/stable/3150853

Calero-Racho, F. M. (2004). The rise of media specialist agencies. Media Asia, 31(4), 224-229. https://doi.or $\mathrm{g} / 10.1080 / 01296612.2004 .11726758$

Callow, M., \& Schiffman, L. (2002). Implicit meaning in visual print advertisements: A cross-cultural examination of the contextual communication effect. Journal of Advertising, 21(2), 259-277. https:// doi.org/10.1080/02650487.2002.11104929

Chen, C.-P., Chen, C.-H., \& Cañete, A. M. (2017). Mirror of beauty: Cultural values reflected in online skincare advertising in the Philippines and Taiwan. Corporate Management Review, 37(2), 127-158. https://ibm.nctu.edu.tw/ibm/cmr/2017_Issue2/Corporate\%20Management\%20Review_2017\%20 Volume\%2037,\%20issue\%202,\%20127-158.pdf

Conlin, L., \& Bissell, K. (2014). Beauty ideals in the checkout aisle: Health-Related messages in women's fashion and fitness magazines. Journal of Magazine and New Media Research, 15(2), 1-19. Retrieved from https://aejmcmagazine.arizona.edu/Journal/Summer2014/ConlinBissell.pdf

Dayag, D. T. (2008). The discourse of print advertising in the Philippines: Generic structures and linguistic features. 22nd Pacific Asia Conference on Language, Information and Computation, (1-15).

EON Group. (2019). Philippine trust index (PTI) 2019: Who's capitalizing on society's new currency? https:// www.eon.com.ph/pti/

Fernandez, E. (2016). Discourse analysis of persuasive language in Philippine print advertising. The Reflective Practitioner, 1, 1-25. http://cas.upm.edu.ph/journals/index.php/the-reflectivepractitioner/article/view/2

Frith, K. T. (1997). Asian advertising: Charting the trends. Media Asia, 24(2), 94-98. https://doi.org/10.108 0/01296612.1997.11726527

Frith, K. T., \& Wesson, D. (1991). A comparison of cultural values in British and American print advertising: A study of magazines. Journalism Quarterly, 68(1/2), 216-223. https://www.researchgate.net/ publication/234668041_A_Comparison_of_Cultural_Values_in_British_and_American_Print_ Advertising_A_Study_of_Magazines

Frith, K. T., Shaw, P., \& Cheng, H. (2005). The construction of beauty: A cross-cultural analysis of women's magazine advertising. Journal of Communication, 55(1), 56-70. https://doi. org/10.1111/j.1460-2466.2005.tb02658.x

Goffman, E. (1987). Gender advertisements. Harper \& Row Publishers, Inc. (Original work published in 1976).

Grau, S. L., \& Zotos, Y. C. (2016). Gender stereotypes in advertising: A review of current research. International Journal of Advertising, 35(5), 761-770. https://doi.org/10.1080/02650487.2016.12035 56

Gross, B. L., \& Sheth, J. N. (1989). Time-oriented advertising: A content analysis of United States magazine advertising, 1890-1988. Journal of marketing, 53(4), 76-83. https://www.jstor.org/stable/1251381 
Jhally, S. (1995). Image-based culture: Advertising and popular culture. In G. Dines, \& J. Humez (Eds.), Gender, race, and class in media (77-87). http://www.anthrocervone.org/PeoplesandCultures/wpcontent/uploads/2012/07/image_based_culture001.pdf

Kang, M.-E. (1997). The portrayal of women's images in magazine advertisements: Goffman's gender analysis revisited. Sex Roles, 37(11/12), 979-996. https://doi.org/https://link.springer.com/ article/10.1007/BF02936350

Khairullah, D. H., \& Khairullah, Z. (2003). Dominant cultural values. Journal of Global Marketing, 16(1-2), 47-70. https://doi.org/10.1300/J042v16n01_03

Kim, K., Hayes, J. L., Avant, A., \& Reid, L. N. (2014). Trends in advertising research: A longitudinal analysis of leading advertising, marketing, and communication journals, 1980 to 2010. Journal of Advertising, 43(3), 296-316. https://doi.org/10.1080/00913367.2013.857620

Krishen, A. S., LaTour, M. S., \& Alishah, E. J. (2014). Asian females in an advertising context: Exploring skin tone tension. Journal of Current Issues and Research in Advertising, 35, 71-85. https://doi.org/10.108 $0 / 10641734.2014 .866851$

LaTour, M., \& Henthorne, T. (1994). Ethical judgments of sexual appeals in print advertising. Journal of Advertising, 23(3), 81-90. https://www.jstor.org/stable/4188942

Lent, J. A. (1969). Advertising in the Philippines. Philippine Studies, 17(1), 72-96. http://www.jstor.org/ stable/42634497

Lerman, D., \& Callow, M. (2004). Content analysis in cross-cultural advertising research: Insightful or superficial? International Journal of Advertising, 23(4), 507-521. https://doi.org/10.1080/02650487 .2004 .11072897

Lin, C.-Y. (2008). Sexual issues: The analysis of female role portrayal preferences in Taiwanese print ads. Journal of Business Ethics, 83(3), 409-418. https://doi.org/10.1007/s10551-007-9628-5

Lynn, S., Walsdorf, K., Hardin, M., \& Hardin, B. (2002). Selling girls short: Advertising and gender images in Sports Illustrated for Kids. Women in Sport \& Physical Activity Journal, 11(2), 77-100. https://doi. org/10.1123/wspaj.11.2.77

Mager, J., \& Helgeson, J. G. (2011). Fifty years of advertising images: Some changing perspectives on role portrayals along with enduring consistencies. Sex Roles, 64, 238-252. https://doi.org/10.1007/ s11199-010-9782-6

Marquez, F. (1975). The relationship of advertising and culture in the Philippines. Journalism Quarterly, 52(3), 436-442. https://doi.org/10.1177/107769907505200305

Print. (n.d.). Media ownership monitor Philippines. https://philippines.mom-rsf.org/en/media/print/

Millard, J. (2009). Performing beauty: Dove's "real beauty campaign". Symbolic Interaction, 32(2), 146-168. https://doi.org/10.1525/si.2009.32.2.146

Morris, P. K. (2006). Gender in print advertisements: A snapshot of representations from around the world. Media Report to Women, 34(3), 13-20. https://ecommons.luc.edu/communication_facpubs/16/

Nyilasy, G., King, K. W., \& Reid, L. N. (2011). Checking the pulse of print media: Fifty years of newspaper and magazine advertising research. Journal of Advertising Research, 51(1), 167-181. https://doi. org/10.2501/JAR-51-1-167-181 
O'Sullivan, J., Fortunati, L., Taipale, S., \& Barnhurst, K. (2017). Innovators and innovated: Newspapers and the postdigital future beyond the "death of print". The Information Society, 33(2), 86-95. https://doi. org/10.1080/01972243.2017.1289488.

Philippine Statistics Authority. (2019). Functional literacy, education, and mass media survey. https:// psa.gov.ph/sites/default/files/2019-FLEMMS-Final-Report_Signed_FULL\%20VERSION_15\%20 January\%202021rev.pdf

Plakoyiannaki, E., \& Zotos, Y. (2009). Female role stereotypes in print advertising: Identifying associations with magazine and product categories. European Journal of Marketing, 43(11/12), 1411-1434. https://doi.org/10.1108/03090560910989966

Pollay, R. W. (1985). The subsiding sizzle: A descriptive history of print advertising, 1900-1980. Journal of Marketing, 49(3), 24-37. https://www.jstor.org/stable/1251613

Robinson, B. K., \&Hunter, E. (2008). Is mom still doing it all? reexamining depictions offamily work in popular advertising. Journal of Family Issues, 29(4), 465-486. https://doi.org/10.1177/0192513X07310311

Schroeder,J.E., \&Zwick, D. (2004). Mirrors of masculinity:Representation and identity in advertising Images. Consumption Markets and Culture, 7(1), 21-52. https://doi.org/10.1080/1025386042000212383

Schwarzkopf, S. (2011). The subsidizing sizzle of advertising history: Methodological and theoretical challenges in the post advertising age. Journal of Historical Research in Marketing, 3(4), 528-548. https://doi.org/10.1108/17557501111183653

Soar, M. (2000). Encoding advertisements: Ideology and meaning in advertising production. Mass Communication and Society, 3(4), 415-437. https://doi.org/10.1207/S15327825MCS0304_05

Stankiewicz, J. M., \& Rosselli, F. (2008). Women as sex objects and victims in print advertisements. Sex Roles, 58, 579-589. https://doi.org/10.1007/s11199-007-9359-1

Thomas, M., \& Treiber, L. A. (2000). Race, gender, and status: A content analysis of print advertisements in four popular magazines. Sociological Spectrum, 20(3), 357-371. https://doi. org/10.1080/027321700405090

West, C., \& Zimmerman, D. H. (1987). Doing gender. Gender and Society, 1(2), 125-151. https://www.jstor. org/stable/189945

Wood, J. T., \& Fixmer-Oraiz, N. (2017). Gendered lives: Communication, gender, \& culture (12th ed.). Cengage Learning.

Yan, Y., \& Bissell, K. (2014). The globalization of beauty: How is ideal beauty influenced by globally published fashion beauty magazines? Journal of Intercultural Communication Research, 43(3), 194214. https://doi.org/10.1080/17475759.2014.917432

Zayer, L. T., \& Coleman, C. A. (2015). Advertising professionals' perceptions of the impact of gender portrayals on men and women: A question of ethics? Journal of Advertising, 44(3), 264-275. https:// doi.org/10.1080/00913367.2014.975878

Zotos, Y. C., \& Tsichla, E. (2014a). Female stereotypes in print advertising: A retrospective analysis. Procedia - Social and Behavioral Sciences, 148, 446-454. https://doi.org/10.1016/j.sbspro.2014.07.064

Zotos, Y. C., \& Tsichla, E. (2014b). Snapshots of men and women in interaction: An investigation of stereotypes in print advertisement relationship portrayals. Journal of Euromarketing, 23(3), 35-58. https://www.researchgate.net/publication/267842958_Snapshots_of_Men_and_Women_in_ Interaction_An_Investigation_of_Stereotypes_in_Print_Advertisement_Relationship_Portrayals 


\section{Endnotes}

${ }^{1}$ For the purposes of this study, "humanoids" pertain to both real people and cartoonized people with defining physical attributes. Included in this definition are characters whose bodies do not appear fully (i.e., half-body shots) but are clearly seen (i.e. with features that signify their sex) and torsos with distinguishable features (e.g., half a woman's body without a head). Disembodied limbs (e.g., hands, arms, legs) were not included unless accompanying text or image specified their gender.

2 Variables that did not have to be tested for reliability are: Product, Campaign, Case ID, Company, and Pitch at the ad-level, and Character ID at the character-level. All were coded as string variables except for the numeric Case and Character IDs.

3 "Identification" in this variable refers to the process of determining the standout characters using uniformly coded names. Celebrity characters were coded with their specific names, while generic characters were coded with simple identifiers (e.g., mother, man in jacket). To ensure uniformity, names that pertained to the same character but were initially encoded differently were recoded to be phrased in the same way.

${ }^{4}$ Print ads do not allow multiple settings, so multiple characters within one ad would only share a single setting. Since characters were the study's point of reference in gendered comparisons, Setting was tested as a character-level variable as the study prioritized situating characters over just determining the setting of an ad.

${ }^{5}$ The study intended to capture queer representation by operationalizing the Gender variable into four different characterizations: cisgender man, cisgender woman, non-cisgender man, and noncisgender woman.

6 "Sulit" is a common Filipino expression used to describe good deals or products that are worth the price.

7 "Wais" roughly pertains to being savvy.

${ }^{8}$ Limbo refers to plain/blank or digital backgrounds. 


\section{Appendix A}

Summary of Variables

\begin{tabular}{cc}
\hline Variable & Description \\
\hline Ad-level variables &
\end{tabular}

Product

Campaign

Case ID

Company

Product Category

Pitch

Setting

Attraction

Ad Composition

Prominence

Standouts
Name of product or service featured in the advertisement

Main text/campaign and title of the ad as encoded in the KANTAR/AIMS database

Numerical identifier of the ad

Name of company/institution that produces/distributes the product or offers the service

General classification of the product or service advertised

Product feature/selling point as presented in the ad

Specific setting of the advertisement

Occurs when characters show signs of liking or romantic/ physical attraction to another character. Includes established and/or married couples and strangers exhibiting attraction to each other. This variable does not concern children and are only applicable to adults. Adapted from Mogaji (2015).

The gender composition of characters in the advertisement

This variable pertains to the characters' general placement in the ad-i.e., who is/are in the foreground or the background, or whose photo is sized bigger than those of other people in the ad.

Number of standout characters. A standout character is defined as an individual humanoid (NOT groups) that meets at least THREE (3) of the following criteria:

1. Focused on by the camera; i.e., clearly seen and not blurred

2. In the middle OR foreground of the photo

3. Relatively bigger in size (in terms of photo placement, not height)

4. Is the endorser of the product

Special instructions: For ads that have multiple iterations of the same person, code iterations separately. 
Character ID

Character name

Credibility

Gender

Age

Social Class

Body Type

Body Shown

Attire

Occupation

Relational Role

Familial Responsibility
Numerical identifier of the character

Name or identifier of the character

The character's role in terms of the product being advertised. A different level of credibility is ascribed to each role.

\section{Gender of character}

Apparent age of the character. This could be depicted visually, mentioned by a character/voice-over, and/or known in the case of a celebrity.

Refers to the character's social standing as depicted in the advertisement. This could be mentioned, or determined through characteristics such as education/occupation, dress, accent, etc. (Adapted from Luyt, 2010)

A character's body type is classified as:

- Endomorphic if it is soft and spherical or rounded in appearance with an underdevelopment of muscle (chubby)

- Mesomorphic if it is hard, rectangular, strong, tough, resistant to injury, and generally equipped for strenuous and exacting physical demands (batak)

- Ectomorphic if it is linear and fragile, characterized by flatness of the chest and delicacy of the body; usually thin and lightly muscled with a physique that is poorly equipped for competitive and persistent physical action (payat)

(Adapted from Sheldon, 1954; Kolbe \& Albanese, 1996 as adapted by Fowler \& Thomas, 2015)

Note: Body type was coded according to how the character is portrayed in the ad. Children were either endomorphic or ectomorphic. Characters shown shoulder up were considered undeterminable.

Portions of body shown in the ad

What a character is shown wearing in the advertisement Specific occupation of the individual character as portrayed in the ad

Specific relational roles of the character as portrayed in the ad. Adapted from Tan, Shaw, Cheng, \& Kim (2013); Mishra (2017); Tartaglia \& Rollero (2015); and Huang \& Lowry (2015)

If the character performs familial duties. Adapted from VallsFernández \& Martínez-Vicente (2007); Verhellen, et al. (2014) 
Use of Hands

Function Ranking

Ritualization of

Subordination

Licensed Withdrawal
An individual model/character's use of hands. Adapted from Goffman (1979) as cited in Mager \& Helgeson (2010)

An individual character's function-in relation to other characters and/or the story/pitch of the ad-as portrayed in any given setting. Adapted from Goffman (1979) as cited in Mager \& Helgeson (2010)

How an individual character is made to appear in terms of posture and placement. Adapted from Goffman (1979) as cited in Mager \& Helgeson (2010)

Pertains to the character's psychological engagement with other characters and/or the situation. Adapted from Goffman (1979) as cited in Mager \& Helgeson (2010) 


\section{Grant Support Details}

Author Contributions: The article is an output of a research program where everyone contributed to the conceptualization, implementation, and reporting of outputs. The collective work in the program includes the writing and presenting of this article, with the lead author at the helm. The authors have read and agreed to the published version of the manuscript.

Funding: This paper is part of a larger research project on Gender Representation in Philippine Advertising that examined advertisements across print media, television, and radio. The project, conducted from 2018 to 2019, was funded by Investing in Women, an initiative of the Australian government.

Acknowledgements: The authors extend their gratitude to Prof. Clarissa C. David for her contributions in the early stages of conceptualization of the study, and to Investing in Women for their unwavering support throughout the conduct of this research.

Conflict of Interest: The authors declare no conflict of interest and have the full support of the funder in the decision to publish the results.

\section{About the Authors}

CZEKAINA ESRAH RAPANOT is a Project Assistant at the Department of Communication Research and a graduate student of Philippine Studies at the UP Asian Center. She has been involved in the Department's academic projects and has also presented her own works in academic conferences. (Corresponding author: carapanot@up.edu.ph)

FERNANDO PARAGAS is a Professor of Communication Research at the UP College of Mass Communication. He has been in the field of communication research since 1997. His studies have been published locally and internationally. In 2019, Dr. Paragas was one of three Gawad Tsanselor sa Natatanging Guro - the highest award bestowed on UP Diliman faculty members. (fcparagas@up.edu. $\mathrm{ph})$

MARRHON MANGALUS works as a Senior Project Assistant in the Higher Education Research and Policy Reform Program of the UP Center for Integrative and Development Studies. She has been working in various qualitative, quantitative, and multi-method research projects since 2016. (marrhon@protonmail. com)

CATHERINE FAITH HOGGANG is pursuing her Juris Doctor degree at the UP College of Law. She worked as a project research assistant for various research projects at the Communication Research Department from 2016-2018. (catherine.hoggang@obf.ateneo.edu)

MARIAM JAYNE AGONOS is currently an Instructor of Communication Research at the UP College of Mass Communication, and a graduate student of Philippine Studies at the UP Asian Center. She has been involved in various academic research projects, and authored a few academic research works as well. (mmagonos@up.edu.ph) 
